\title{
A PERCEPÇÃO DA POPULAÇÃO SOBRE ARBORIZAÇÃO EM UM CONJUNTO HABITACIONAL NO MUNICÍPIO DE PARAGOMINAS-PA
}

\author{
POPULATION PERCEPTION ABOUT AFFORESTATION IN A HOUSING COMPLEX \\ IN THE MUNICIPALITY OF PARAGOMINAS, PARÁ
}
Victor Pereira de Oliveira ${ }^{1}$, Joaquim Gabriel Siqueira Dias², Alaene Teixeira Ribeiro³, Luana Bianca da Silva Oliveira ${ }^{4}$, Mariana de Oliveira Mariano ${ }^{5}$, Danielle Silva Pinto ${ }^{6}$

\section{RESUMO}

Este estudo teve por objetivo gerar um diagnóstico da percepção dos moradores em relação à arborização em um conjunto habitacional em Paragominas, Pará. A metodologia utilizada baseou-se na aplicação de questionários com perguntas objetivas e subjetivas. A aplicação dos questionários foi realizada por meio de amostragem aleatória, baseada na estatística de $10 \%$ do número de residências, totalizando 110 entrevistados. Os resultados demonstram que a população necessita de espaços mais arborizados, os quais irão proporcionar maior conforto térmico, sendo relatado como os maiores benefícios a sombra e redução de calor, com $48 \%$ e $42 \%$, respectivamente. $8 \%$ dos entrevistados consideram que a arborização possui desvantagens, sendo relatada a sujeira nas calçadas, causada principalmente pelas folhas e frutos como a principal. A maioria dos moradores mostraram interesse em participar de projetos de arborização e ressaltaram a necessidade de programas de educação ambiental, principalmente para o cuidado com as mudas. Os moradores escolheram como principal espécie a ser plantada o ipê (Handroanthus spp. Mattos), devido a suas flores vistosas e coloridas. Os moradores mostraram ser conscientes que a prefeitura é a responsável por projetos de arborização, bem como que o vandalismo é uma das causas que mais prejudica a falta de árvores no conjunto.

Palavras-chave: Percepção; Conforto térmico; Arborização; Educação ambiental; Vandalismo.

\begin{abstract}
This study aimed to generate a diagnostic of the afforestation perception of residents in a housing complex in Paragominas, Pará. The methodology consisted on the application of questionnaires with objective and subjective questions. The application of the questionnaires was conducted through random survey, based on the statistics of $10 \%$ of the number of residents, totaling 110 interviewed residents. The results show that the population needs more afforested areas, which will provide higher thermal comfort, being related as the greatest benefits shade and reduction of heat, with $48 \%$ and $42 \%$, respectively. $8 \%$ of the participants considered as main disadvantage the litter on the sidewalks caused mainly by leaves and fruits. In general, most of the residents demonstrated interest on participating on afforestation projects and mentioned the necessity of ecological awareness programs, principally for the saplings care. The residents chose ipê (Handroanthus spp. Mattos) as principal species to be planted, due its colorful and attractive flowers, however, residents also reported fruitful species for its fruits utilization, principally mango tree (Mangifera indica L.). The residents demonstrated to be aware that city hall is responsible for afforestation projects, as well as vandalism is one of the reasons that jeopardize the most the quantity of trees in the housing complex.
\end{abstract}

Keywords: Environmental perception; Thermal comfort; Afforestation; Environmental education; Vandalism.

\footnotetext{
Recebido em 31.05.2017 e aceito em 02.10.2017

1 Graduando em Engenharia Florestal. Universidade Federal Rural da Amazônia (UFRA). Paragominas/PA. Email: olivervp09@yahoo.com.br

2 Graduando em Engenharia Florestal. UFRA. Paragominas/PA. Email: joaquimgdias@gmail.com

3 Graduanda em Engenharia Florestal. UFRA. Paragominas/PA. Email: alaene.ribeiro@hotmail.com

4 Graduanda em Engenharia Florestal. UFRA. Paragominas/PA. Email: luanna.oliveira947@gmail.com

5 Graduanda em Engenharia Florestal. UFRA. Paragominas/PA. Email: marianaoliver04@gmail.com

6 Engenheira Florestal. Doutora. Professora Adjunta I da UFRA. Paragominas/PA. Email: danielle.pinto@ufra.edu.br
} 


\section{INTRODUÇÃO}

No decorrer dos anos, o índice de concentração nos centros urbanos aumentou consideravelmente, o que gerou o desenvolvimento de cidades e interferência direta de ações antrópicas no meio ambiente. Esta relação entre homem e natureza, em sua maior parte, resultou em ocupação e crescimentos desordenados, ocasionando áreas habitadas com vestígios florísticos.

A arborização presente no ambiente urbano pode proporcionar diferentes funções ecológicas, tais como: redução da poluição do ar, elevação da umidade relativa, amenizar ruídos, servir como referencial urbano, valorização estética e, ainda, satisfazer os requisitos sociais e econômicos (OLIVEIRA et al., 2017), além disso, ambientes mais arborizados apresentam um clima diferenciado e, por consequência, mais agradável.

Conforme Rodrigues et al. (2010), não obstante reconhecida importância da arborização das áreas urbanas, é corriqueiro o fracasso dos plantios ou da manutenção dessas áreas, o que se deve principalmente à falta da participação comunitária e da ausência de conscientização sobre a importância da arborização, haja vista que para um planejamento eficiente e manutenção da arborização é necessário considerar a percepção da população local.

Trabalhos como de Melazo (2005), Oliveira (2006), Freitas e Ribeiro (2007), Bezerra e Gonçalves (2007), Marin (2008) e Batista et al. (2013) enfatizam a importância de atividades de planejamento voltadas à percepção ambiental da sociedade, de modo que a compreensão das inter-relações entre o homem e o ambiente e a concepção sobre como cada indivíduo reage frente às ações sobre o meio sejam avaliadas. Pode-se dizer que o estudo da percepção ambiental da população possibilita obter informações importantes para a gestão sustentável das cidades, incluindo os processos relacionados à arborização de suas ruas.

Em 2008, o município de Paragominas, foi um dos pioneiros no desenvolvimento e implantação do conceito "Município Verde", o que lhe permitiu a condição de ser o primeiro município a sair da lista de municípios críticos de desmatamento (GUIMARÃES et al., 2013), porém o mesmo apresenta pouca distribuição de vegetação em localidades centrífugas. Desse modo, estudos que visam contribuir com informações adequadas para o desenvolvimento do município são consideravelmente importantes e incipientes.

Mediante o exposto, o presente trabalho teve como objetivo, avaliar a percepção dos moradores em relação à arborização do conjunto habitacional Morada dos Ventos no município de Paragominas, Pará. 


\section{MATERIAL E MÉTODOS}

\section{Caracterização da área de estudo}

O estudo foi realizado no conjunto habitacional Morada dos Ventos na cidade de

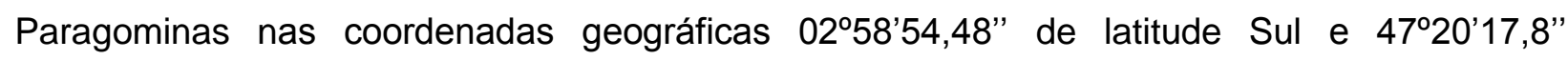
longitude Oeste, a $72 \mathrm{~m}$ de altitude, a área está demarcada em vermelho (Figura 1). A escolha da área de estudo se justifica pois o conjunto habitacional é o maior em extensão do município, com 1.100 unidades habitacionais em que se percebe uma certa carência em projetos que aumentem a qualidade de vida da população. Paragominas está situado na mesorregião sudeste do Pará, a 320 quilômetros da capital, Belém. Possui clima do tipo quente e úmido, com temperatura média anual de $26,3^{\circ} \mathrm{C}$ e umidade relativa do ar média de $81 \%$, a pluviosidade média anual é de 1.800 milímetros, com um período mais chuvoso entre os meses de dezembro a maio, e outro mais seco entre junho e novembro (PINTO et al., 2009).

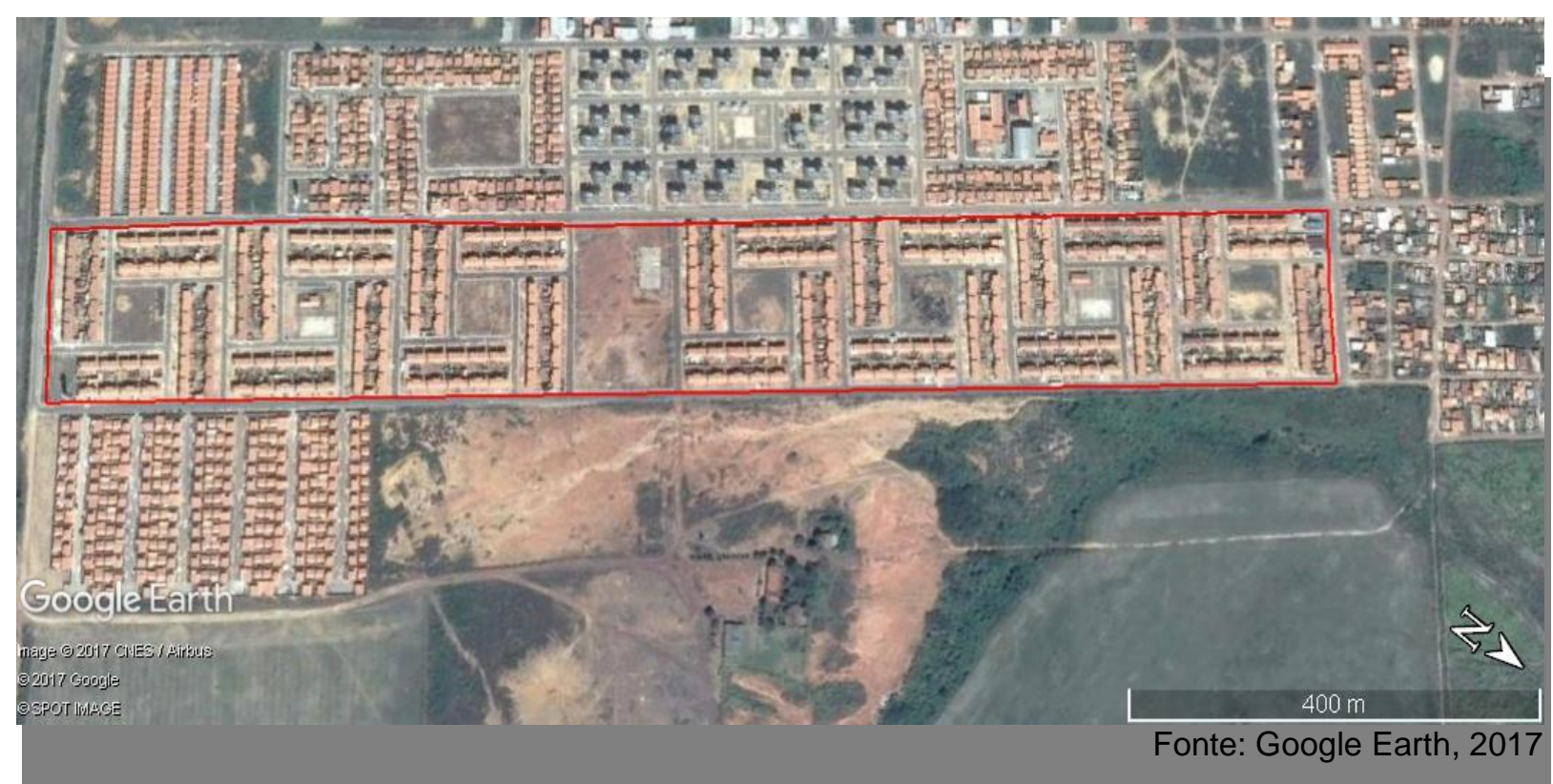

Figura 1. Localização do Conjunto Habitacional Morada dos Ventos em Paragominas, Pará

Figure 1. Location of the housing complex Morada dos Ventos in Paragominas, Pará

\section{Metodologia}

A metodologia utilizada para esse estudo se desenvolveu com a aplicação de questionários semi-estruturados com questões discursivas e objetivas, sendo feita de forma aleatória para os residentes da área de estudo. O critério de escolha dos participantes foi, essencialmente, serem moradores da área, e determinou-se para o número de entrevistas 
realizadas a estatística de $10 \%$ do total de moradores do conjunto habitacional, adaptada a partir da metodologia proposta por Roppa et al. (2007) e Souza, Cardoso e Silva (2013).

Os questionários foram aplicados entre os meses de setembro a novembro de 2016, com as seguintes informações: número de moradores por residência, grau de escolaridade, grau de arborização da rua, vantagens e desvantagens apresentadas pela arborização, forma de colaboração por parte dos moradores a manutenção, a indicação de espécies que estes desejariam que fossem implantadas e o que deveria ser feito para melhorar a urbanização do bairro, caso fosse desenvolvido.

Depois de realizada as entrevistas, procederam-se a tabulação e análise dos dados obtidos, a fim de observar os reflexos sobre a percepção da população em relação a arborização por meio de planilhas informatizadas, utilizando o software Microsoft Excel 2013.

\section{RESULTADOS E DISCUSSÃO}

Foram aplicados um total de 110 questionários no conjunto habitacional Morada dos Ventos. A maioria dos entrevistados são do sexo feminino, correspondendo à um percentual de $66,36 \%$ do sexo feminino, e $33,64 \%$ do sexo masculino. Durante as entrevistas, os moradores puderam responder não apenas às questões que lhes foram propostas, como também se deparar com questões que lhes deram a oportunidade de refletir acerca de suas atitudes e de seus conceitos sobre a arborização urbana.

Sobre o enquadramento residencial, constatou-se que, cerca de $52,72 \%$ das residências possuem de 3 a 4 moradores, 26,36\% de 5 a 6 moradores, $18,18 \%$ de 1 a 2 moradores e 2,72\% apresentam mais de 6 moradores. Neste sentido, observou-se que, no conjunto habitacional estudado, o núcleo familiar é constituído, em sua maioria, por no máximo 4 moradores.

Em relação ao grau de escolaridade dos entrevistados, 32,72\% possuem ensino fundamental incompleto, $22,72 \%$ ensino médio completo, $18,18 \%$ ensino médio incompleto, $12,72 \%$ ensino fundamental completo, $7,27 \%$ ensino superior incompleto, $4,55 \%$ ensino superior e 1,82\% não são alfabetizados.

Quando indagados sobre a classificação de arborização da rua onde vivem, 70,91\% dos moradores consideram pouco arborizado, $20 \%$ razoavelmente arborizado e $9,09 \%$ muito arborizado. Apesar de alguns participantes terem dúvidas sobre o conceito de arborização, ainda assim, observou-se que o maior percentual se concentrou na consideração de escassez de arborização nas ruas. 
No que se refere as vantagens da arborização, a maioria dos entrevistados, 48,18\%, consideraram a sombra a maior vantagem da arborização, 41,82\% reputaram a redução do calor, $8,18 \%$ presença de flores e frutos e 1,81\% a redução da poluição sonora (Figura 2).

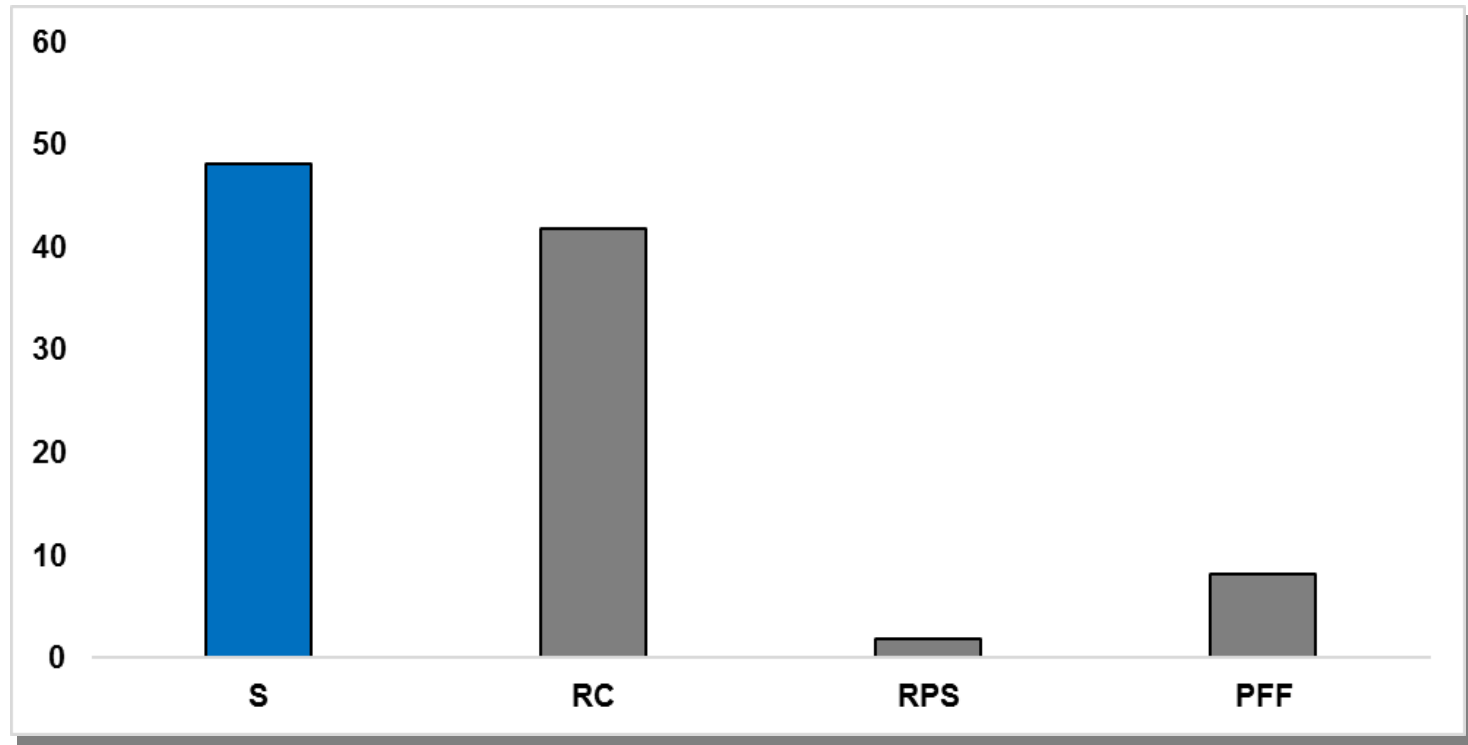

Figura 2. Vantagens na arborização urbana observadas pela população do conjunto habitacional Moradas dos Ventos, em Paragominas, Pará. ( $\mathrm{S}=$ Sombra; RC=Redução do Calor, RPS=Redução da Poluição Sonora e PFF=Presença de Flores e Frutos)

Figure 2. Advantages of the afforestation observed by the population of Morada dos Ventos housing complex, in Paragominas, Pará. $(\mathrm{S}=$ Shade, $\mathrm{RC}=$ Reduction of Heat, RPS $=$ Reduction of Sound Pollution and PFF = Presence of Flowers and Fruits)

A obtenção de maiores percentuais na sombra e redução do calor como maiores vantagens da arborização, pode ser explicado devido ao questionário ter sido aplicado no período do verão amazônico já que, conforme o Instituto Nacional de Meteorologia (INMET) (2017), a cidade de Paragominas apresenta média de temperatura máxima de $26,6^{\circ} \mathrm{C}$, mas com registros acima de $34^{\circ} \mathrm{C}$. De acordo com os trabalhos de Roppa et al. (2007) e Silva et al. (2015), a consideração dos entrevistados referente à maior vantagem da arborização, consiste na sombra e em seguida a redução do calor, o que evidencia que os moradores sentem a necessidade da melhoria do microclima urbano, bem como o conforto térmico. No estudo realizado por Targino, Krecl e Coraiola, (2013) foi verificado que a temperatura média diária aumenta $6^{\circ} \mathrm{C}$ em áreas sem predominância da vegetação na região central de Londrina-PR.

De outro modo, também foi questionado sobre a existência de desvantagem na arborização. Mais de $91 \%$ dos moradores consideraram que não existem desvantagens, inversamente $8,18 \%$ supuseram haver desvantagens, sendo relacionadas, com $55,56 \%$ à sujeira de ruas e calçadas, e os demais itens como sujeira provocada pelos pássaros, redução da iluminação pública, problemas com a rede elétrica e problemas nas calçadas, com 11,11\% 
respectivamente. Segundo estudos de Castro e Dias (2013) e Souza, Cardoso e Silva (2013) foi relatado como principal desvantagem a sujeira nas ruas e calçadas, principalmente pela senescência das folhas, o que corrobora com os resultados encontrados nesse estudo.

A população demonstrou interesse em colaborar com a arborização, constatou-se que 95,45\% dos entrevistados responderam que auxiliariam na arborização do conjunto habitacional. Destes, 47,61\% colaborariam plantando árvores, 35,24\% colaborariam não danificando e $17,14 \%$ fazendo a manutenção e poda, sendo a última uma atividade que deve ser executada apenas por pessoas habilitadas e treinadas para que não ocasione danos ao meio físico.

Outro ponto analisado foi o que a população acredita que deve ser feito para melhorar a arborização local. Mais de $46 \%$ dos entrevistados acredita que promover um trabalho de educação ambiental trará benefícios para a arborização, 39,09\% pensam na implantação de mais árvores, $13,64 \%$ na manutenção e poda no tempo adequado e $0,9 \%$ responderam outros (Figura 3).

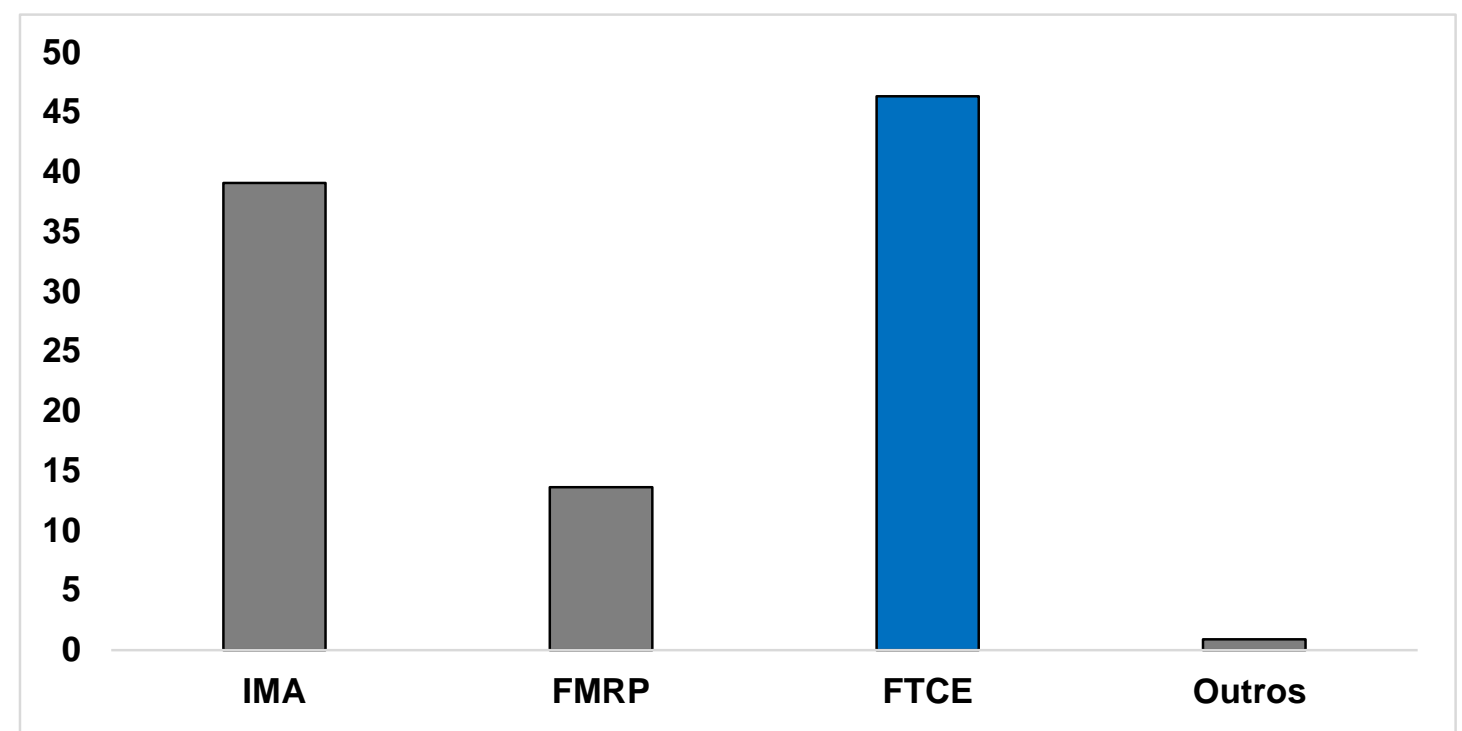

Figura 3. Principais itens relacionados para a melhoria da arborização do conjunto habitacional Morada dos Ventos em Paragominas, Pará. (IMA=Implantar mais árvores; FMRP=Fazer manutenção e realizar podas em épocas adequadas; FTCE=Fazer um trabalho de conscientização ecológica)

Figure 3. Main related items for the improvement of the afforestation of the housing complex Morada dos Ventos in Paragominas, Pará (IMA = Implanting more trees; FMRP = Maintenance and pruning at appropriate times; FTCE $=$ Realize an ecological awareness project)

$\mathrm{Na}$ abordagem sobre a solicitação de responsável para arborização de ruas, observouse que 90,91\% solicitariam à Prefeitura Municipal, 7,27\% companhias de telefonia e energia e $1,82 \%$ a outros. Percebe-se, assim, que os moradores têm conhecimento de que a prefeitura municipal é a principal responsável por desenvolver projetos de arborização das ruas da 
cidade. Os resultados de Castro e Dias (2013) em Macapá, Amapá, apresentaram que 60\% optaram por encaminhar a solicitação de arborização a outros órgãos, como Secretária de Meio Ambiente (SEMA), IBAMA, bombeiros e outros disseram não saber responder.

Ao serem indagados sobre a possibilidade de um espaço arborizado propiciar melhor qualidade de vida, $100 \%$ dos entrevistados concordaram que a qualidade de vida aumenta quando se tem um espaço arborizado. Seguindo a mesma lógica, foi questionado também se consideravam o conjunto onde moravam arborizado, 84,55\% afirmaram que não consideram o conjunto arborizado e 15,45\% arborizado. Segundo Roppa et al. (2007), existe uma subjetividade em relação a percepção da arborização, sendo muitas vezes levado em consideração apenas as árvores que estão na rua ou na calçada, ao invés de todo o bairro, ocasionando, assim, uma percepção não abrangente.

A respeito da preferência de espécies no conjunto habitacional, apresentou-se no questionário espécies frequentemente utilizadas nas calçadas, e inferiu-se que, 48,18\% dos entrevistados optariam pelo plantio de Handroanthus spp. Mattos. (ipê), 23,64\% por Licania tomentosa (Benth.) Fritsch. (oití), 21,82\% por Delonix regia (Hook.) Raf. (flamboyant), 4,55\% Dalbergia melanoxylon Guill. e Perr. (pau-preto) e 1,82\% Acacia mearnsii Wild. (acácia-negra) (Figura 4).

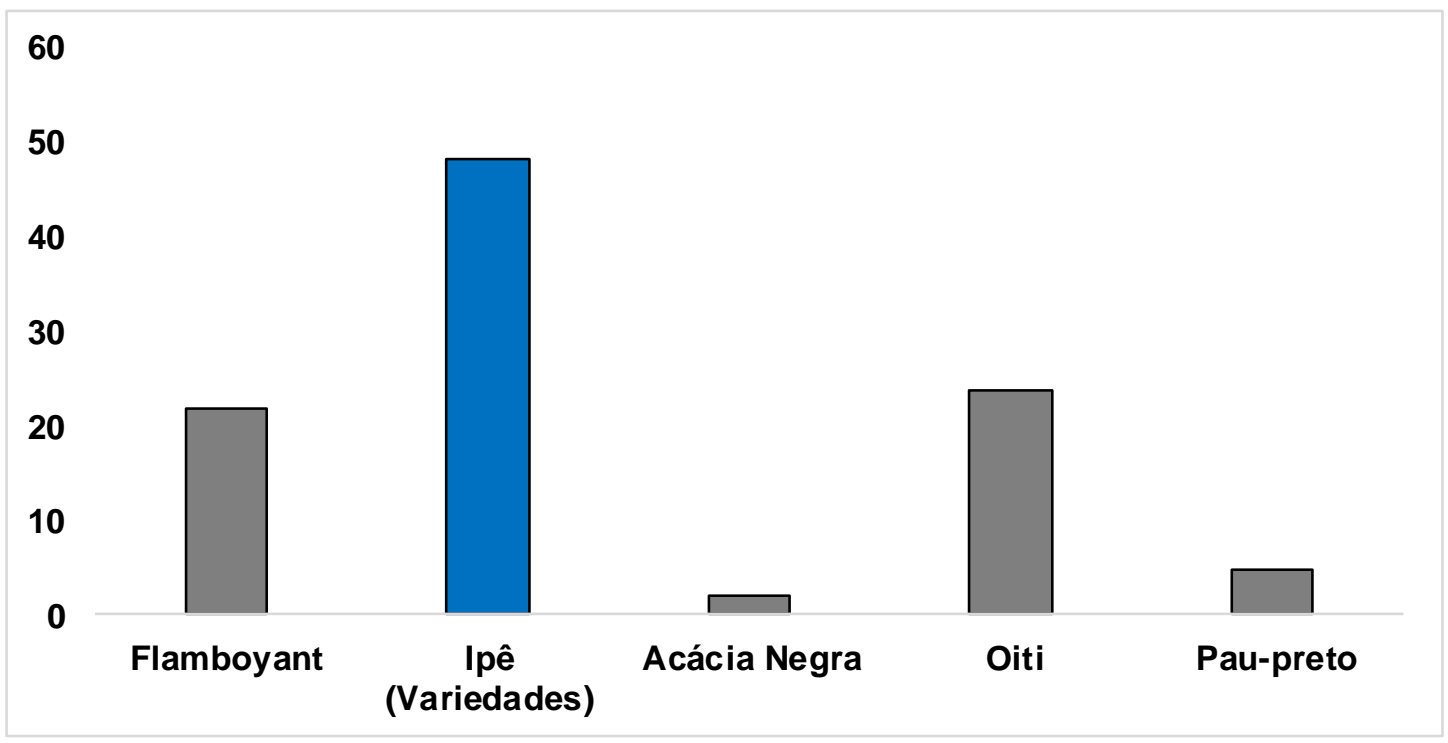

Figura 4. Espécies sugeridas no questionário para arborização do conjunto habitacional Morada dos Ventos no município de Paragominas, Pará

Figure 4. Species suggested in the questionnaire for afforestation of Morada dos Ventos housing complex in the municipality of Paragominas, Pará

Além destas acima, os moradores, sugeriram espécies como Mangifera indica L. (mangueira), Terminalia catappa L. (castanhola), Caesalpinia echinata Lam. (pau-brasil), 
Eucalyptus spp, Syzygiumma laccense L. (jambeiro) e Anacardium occidentale L.(cajueiro). Essas sugestões foram relacionadas principalmente para as espécies frutíferas, pois, segundo os próprios moradores, seria relevante para a alimentação da própria comunidade. Estas espécies são comumente encontradas em arborização urbana em várias regiões do Brasil (SILVA et al., 2007; ROSSATTO; TSUBOY; FREI, 2008; COLETTO; MULLER; WOLSKI, 2008; SERPA; MORAIS; MOURA, 2009).

Concernente à interrogativa referente à participação em oficinas de educação ambiental, caso estas fossem realizadas, $85,45 \%$ afirmaram participação e, antagonicamente, $14,55 \%$ declararam que não participariam, seja por outros compromissos e/ou simplesmente falta de interesse.

Dentre outros, um dos principais aspectos realçados pelos entrevistados que cerceia a arborização no conjunto habitacional, concerniu às práticas de vandalismo após a implantação de mudas, sendo especificado que os principais responsáveis por tal delito são as crianças e adolescentes, necessitando, desse modo, atividades de conscientização e educação ambiental assim como trabalhos sociais que utilizem o tempo ocioso dos mesmos. De acordo o trabalho de Ho et al. (2015) na região central de Mandirituba-PR, o fator que mais impede o desenvolvimento das árvores no meio ambiente é o vandalismo e pavimentação das calçadas, o que corrobora a afirmativa dos entrevistados quanto a esse fato.

\section{CONCLUSÕES}

Diante dos resultados expostos, observa-se que, em geral, a comunidade do conjunto habitacional Morada dos Ventos entende a importância da arborização no contexto urbano e seus benefícios à qualidade de vida. Percebeu-se também que o grau de escolaridade refletiu nas respostas e na elaboração de sugestões para melhoria da arborização. Em relação ao levantamento das espécies, os moradores escolheram a que, esteticamente, mais os atraem pela beleza das flores, entre elas o ipê e flamboyant, contudo, também escolheram espécies frutíferas principalmente para uso na própria alimentação.

Além disso, os moradores perceberam a falta de espaços verdes no conjunto e mostraram-se interessados em participar de ações que aumente a arborização, os mesmos consideram que, para melhores resultados, é necessário maior conscientização ambiental. É importante que os órgãos públicos, principalmente a prefeitura, se empenhem em campanhas educativas com o objetivo de sensibilizar os moradores sobre a importância da arborização que vise aumentar as áreas verdes para maior qualidade ambiental e conforto térmico. 
Dessa forma, os moradores do conjunto habitacional estão, em sua maioria, cientes que não é suficiente apenas plantar árvores para o bem estar da comunidade, devendo ser feito conjuntamente um trabalho de conscientização com todos os envolvidos, pois, somente assim, será eficiente um projeto de arborização.

\section{REFERÊNCIAS}

BATISTA, F. A.; CHAVES, T. P.; FELISMINO, D. C.; DANTAS, I. C. Inventário quali-quantitativo da arborização urbana na cidade de Remígio, Paraíba. Revista de Biologia e Farmácia Campina Grande, v. 9, n. 1, p. 70-83, 2013.

BEZERRA, T. M. O.; GONÇALVES, A. A. C. Concepções de meio ambiente e educação ambiental por professores da Escola Agrotécnica Federal de Vitória de Santo Antão-PE. Revista Biotemas, Florianópolis, v. 20, n. 3, p. 115-125, 2007.

CASTRO, H. S.; DIAS, T. C. A. C. Percepção Ambiental e Arborização Urbana em Macapá, Amapá. Revista Biota Amazônia, Macapá, v. 3, n. 3, p. 34-44, 2013.

COLETTO, E. P.; MÜLLER, N. G.; WOLSKI, S. S. Diagnóstico da arborização das vias públicas do Município de Sete de Setembro-RS. Revista da Sociedade Brasileira de Arborização Urbana, Piracicaba, v. 3, n. 2, p. 110-122, 2008.

FREITAS, R. E.; RIBEIRO, K. C. C. Educação e percepção ambiental para a conservação do meio ambiente na cidade de Manaus uma análise dos processos educacionais no centro municipal de educação infantil Eliakin Rufino. Revista Eletrônica Aboré, Manaus, v. 1, n. 3, 2007.

GOMES, R. K. S.; NAKAYAMA, L. Saberes e percepções de meio ambiente dos (as) professores(as) de uma escola ribeirinha amazônica amapaense. Revista COCAR, Belém, v. 10, n. 20, p. 406-430, 2016.

GUIMARÃES, J.; VERÍSsIMO, A.; AMARAL, P.; PINTO, A.; DEMACHKI, A. Municípios verdes: caminhos para a sustentabilidade. IMAZON, Belém: IMAZON. 2013.

HO, T. L.; KOVALSYKI, B.; ZAMPRONI, K.; BIONDI, D. Percepção dos moradores sobre a arborização de ruas da região central de Mandirituba/PR. Revista da Sociedade Brasileira de Arborização Urbana, Piracicaba, v. 10, n. 3, p. 14-23, 2015.

INSTITUTO NACIONAL DE METEOROLOGIA (INMET). Disponível em: < http://www.inmet.gov.br/portal/index.php?r=clima/normaisClimatologicas $>$. Acesso em: 13 Fev 2017.

MARIN, A. A. Pesquisa em educação ambiental e percepção Ambiental. Pesquisa em Educação Ambiental, Ribeirão Preto, vol. 3, n. 1, p. 203-222, 2008.

MELAZO, G. C. Percepção ambiental e educação ambiental: uma reflexão sobre as relações interpessoais e ambientais no espaço urbano. Olhares \& Trilha S, Uberlândia, Ano VI, n. 6, p. 45-51, 2005. 
OLIVEIRA, L. M.; SANTOS, A. F.; SOUZA, P. A.; ALVES, K. C. C. L F.; GIONGO, M. Diagnóstico da arborização nas calçadas de Gurupi, TO. Revista da Sociedade Brasileira de Arborização Urbana, Piracicaba, v. 12, n. 1, p. 105-121, 2017.

OLIVEIRA, N. A. S. A educação ambiental e a percepção fenomenológica, através de mapas mentais. Rev. Eletrônica Mestr. Educ. Ambient. Rio Grande, v.16, p. 32-46, 2006.

PINTO, A.; AMARAL, P.; JÚNIOR, C. S.; VERÍSSIMO, A.; SALOMÃO, R. GOMES, G.; BALIEIRO, C. Diagnóstico Socioeconômico e Florestal do Município de Paragominas. Relatório Técnico. Belém/PA: IMAZON. Belém 2009.

RODRIGUES, T. D.; MALAFAIA, G.; QUEIROZ, S. É. E.; LIMA, A. S. Percepção sobre arborização urbana de moradores em três áreas de Pires do Rio - GOIÁS. Revista de estudos ambientais (Online), Blumenau, v.12, n. 2, p. 47-61, 2010.

ROSSATTO, D. R.; TSUBOY, M. S. F.; FREI, F. Arborização urbana na cidade de Assis-SP: uma abordagem quantitativa. Revista da Sociedade Brasileira de Arborização Urbana, Piracicaba, v. 3, n. 3, p. 1-16, 2008.

ROPPA, C.; FALKENBERG, J. R.; STANGERLIN, D. M.; BRUN, F. G. K.; BRUN, E. J.; LONGHI, S. J. Diagnóstico da percepção dos moradores sobre a arborização urbana na Vila Estação Colônia - bairro Camobi, Santa Maria - RS. Revista da Sociedade Brasileira de Arborização Urbana, Piracicaba, v. 2, n. 2, p. 11-30, 2007.

SERPA, D. S.; MORAIS, N. A.; MOURA, T. M. Arborização urbana em três municípios do sul do estado de Goiás: Morrinhos, Goiatuba e Caldas Novas. Revista da Sociedade Brasileira de Arborização Urbana, Piracicaba, v. 4, n. 3, p. 98-112, 2009.

SILVA, E. C. R.; ALVES, F. B.; SILVA, I. I. S.; CARVALHO, B. C.; ALMEIDA, J. M.; MAGALHÃES, F. C. Percepção da população quanto à arborização na zona central histórica de Altamira-PA. Revista da Sociedade Brasileira de Arborização Urbana, Piracicaba, v. 10, n. 3, p. 24-37, 2015.

SILVA, L. M.; HASSE, I; MOCCELIN, R.; ZBORALSKI, A. R. Arborização de vias públicas e a utilização de espécies exóticas: o caso do bairro Centro de Pato Branco/PR. Scientia Agrária, Curitiba, V. 8, n. 1, p. 47-53, 2007.

SOUZA, S. M.; CARDOSO, A. L.; SILVA, A. G. Estudo da percepção da população sobre a arborização urbana, no município de Alegre-ES. Revista da Sociedade Brasileira de Arborização Urbana, Piracicaba, v. 8, n. 2, p68-85, 2013.

TARGINO, A. C.; KRECL, P. A; CORAIOLA, G. C. Effects of the largescale atmospheric circulation on the onset and strength of urban heat islands: a case study. Theoretical and Applied Climatology, Heidelberg, v. 117, n. 1, p. 73-87, 2013. 